Rev Inv Vet Perú 2011; 22 (3): 268-273

\title{
PREVALENCIA DE TUBERCULOSIS CAPRINA EN LA PROVINCIA DE BARRANCA
}

\author{
Prevalence of Goat Tuberculosis in Barranca, Peru
}

Gino Vergara M. ${ }^{\text {, Alfredo Delgado C., }}{ }^{1,2}$

\section{Resumen}

El presente estudio tuvo como objetivo determinar la prevalencia de la tuberculosis caprina en cuatro distritos de la provincia de Barranca-Lima (Paramonga, Pativilca, Barranca y Supe). Se utilizó la prueba intradérmica única de tuberculina (PPD bovina), basada en la reacción de hipersensibilidad retardada, en 412 caprinos criollos mayores de dos meses de edad, criados de manera extensiva y sedentaria. El antígeno se aplicó en el pliegue caudal y la lectura se realizó a las 72 horas después. Se encontró dos animales reactores (positivos), lo que determinó una prevalencia del $0.48 \pm 0.67 \%$. Los resultados sugieren que la tuberculosis se encuentra poco difundida en los caprinos en la provincia de Barranca.

Palabras clave: prevalencia, tuberculosis caprina, prueba intradérmica, tuberculina, PPD bovina, hipersensibilidad retardada

\section{Abstract}

The objective of the present study was to determine the prevalence of goat tuberculosis in districts of the Barranca province, Lima (Paramonga, Pativilca, Barranca and Supe). The unique intradermal test of tuberculin using bovine purified protein derivative (PPD), based on the delayed hypersensitivity reaction was used. A total of 412 criollo goats, older than two months of age, reared in an extensive system, were tested. The antigen was inoculated in the caudal fold of the tail and the reaction was observed 72 hours later. Two animals were positive, determining a prevalence of $0.48 \pm 0.67 \%$. The results suggest that tuberculosis is scarcely spread in goats of the Barranca province.

Key words: prevalence, goat tuberculosis, intradermal test, tuberculin, bovine PPD, delayed hypersensitivity reaction

\footnotetext{
${ }^{1}$ Clínica de Animales Mayores, Facultad de Medicina Veterinaria, Universidad Nacional Mayor de San Marcos, Lima

${ }^{2}$ E-mail: aldelgadoc@gmail.com
} 


\section{INTRODUCCIÓN}

La tuberculosis (TBC) es típicamente una enfermedad infecciosa de curso crónico que afecta al hombre así como a los animales domésticos y silvestres; y es ocasionada por bacterias (bacilos) del género Mycobacterium (Jubb et al., 1990; Perea et al., 1999). Se reconocen tres tipos principales de bacilos tuberculosos: Mycobacterium tuberculosis (principal causante de la tuberculosis humana), M. bovis (tuberculosis bovina) y $M$. avium (tuberculosis aviar), los cuales pueden producir infección en especies distintas de las propias (Aiello y Mays, 2000).

Las micobacterias son pequeños bacilos aerobios, inmóviles, no formadores de esporas y considerados como parásitos intracelulares facultativos, ya que pueden sobrevivir dentro de los macrófagos. Además, poseen una pared celular muy rica en contenido lipídico, en particular el ácido micólico, el cual le brinda la propiedad de ácido-alcohol resistente, característica de las micobacterias y que se demuestra a través del método de Ziehl-Neelsen (Nicolet, 1986; Cotrina, 1987; Cotran et al., 2000; Prescott et al., 2002).

El agente causal de la tuberculosis caprina es el M. bovis. Después de los bovinos, los caprinos muestran gran susceptibilidad a este germen y tienen, al parecer, cierta resistencia natural al $M$. tuberculosis y $M$. avium (Juste, 1989; Bonilla, 2001; Radostits et al., 2002). La principal fuente de infección por $M$. bovis para muchas especies de mamíferos, incluido el hombre, la constituye el ganado bovino infectado (Acha y Szyfres, 1986; Cotrina, 1987; Blaha, 1995; Radostits et al., 2002). En las cabras, la ruta de infección más común parece ser la aerógena (inhalación), ya que las lesiones primarias se encuentran casi siempre en los pulmones (Beer, 1981; De la Vega, 1988; Jubb et al., 1990). Las lesiones de carácter granulomatoso causadas por M. bovis en los pulmo- nes y ganglios linfáticos de los caprinos son similares a las evidenciadas en los bovinos. En las cabras, además, se observan nódulos caseosos en hígado, bazo, intestinos y ganglios mesentéricos; pudiendo aparecer nódulos circunscritos en la ubre (mastitis tuberculosa) (Beer, 1981; Juste, 1989; Perea et al., 1999; Aiello y Mays, 2000; Torres et al., 2000; Bonilla, 2001).

La bronconeumonía es la forma más frecuente de la TBC en los caprinos y se manifiesta por tos y disnea terminal. También puede cursar con adelgazamiento crónico y progresivo, pelo hirsuto y disminución considerable de la producción láctea (Gázquez, 1991; Perea et al., 1999; Radostits et al., 2002). Tanto la producción de las lesiones granulomatosas características, así como la inmunidad frente a la TBC dependen de las respuestas mediadas por células. En este tipo de inmunidad participan principalmente linfocitos T (Th1) y macrófagos. Estos últimos son activados por linfoquinas (citocinas) secretadas por linfocitos T específicamente sensibilizados, que responden a antígenos procesados, liberados por macrófagos previamente infectados (Jubb et al., 1990; Tizard, 1998; Radostits et al., 2002).

En el Perú, a pesar de la importancia socioeconómica de la producción caprina, existe escasa información sobre la situación sanitaria de los caprinos al encontrarse en manos de familias campesinas de escasos conocimientos. Sin embargo, para estos productores la crianza de cabras representa una fuente importante de ingresos por la venta de quesos y cabritos (Arroyo y Matossian, 2001). No se dispone de estudios epidemiológicos sobre la tuberculosis caprina; pero su presencia podría tener implicancia en la salud de las personas, tomando en cuenta el carácter zoonótico de esta enfermedad y los hábitos alimenticios de algunos sectores de la población, como el consumo de queso fresco de cabra elaborada a partir de leche sin pasteurizar. 
Cuadro 1. Estratificación del número muestral de caprinos según la población de los distritos bajo evaluación en la provincia de Barranca

\begin{tabular}{lcc}
\hline Distrito & Población & $\begin{array}{c}\text { Estratificación } \\
\text { de la muestra }\end{array}$ \\
\hline Paramonga & 1,847 & 72 \\
Pativilca & 2,138 & 83 \\
Barranca & 1,221 & 47 \\
Supe & 4,738 & 183 \\
\hline Total & 9,944 & 385 \\
\hline${ }^{1}$ Fuente: INEI (1994)
\end{tabular}

Por todo lo anterior, el presente estudio tuvo como objetivo determinar la prevalencia de la tuberculosis caprina en la provincia de Barranca, departamento de Lima, mediante la prueba intradérmica única de tuberculina.

\section{Materiales y Métodos}

El estudio se llevó a cabo en los distritos de Paramonga, Pativilca, Barranca y Supe de la provincia de Barranca (0-81 msnm), ubicados a unos $180 \mathrm{~km}$ al norte de la ciudad de Lima.

Los animales muestreados fueron elegidos de 24 hatos de caprinos criollos, criados en forma extensiva y sedentaria por familias campesinas. El tamaño muestral $(n=385)$ fue obtenido al considerarse una prevalencia referencial del $50 \%$, debido a que no se conocen estudios anteriores sobre la prevalencia de la enfermedad en la zona de estudio (Ahlbom y Norell, 1990; Daniel, 1996). El número de animales se estratificó según la población caprina en los distritos muestreados (INEI, 1994), mediante la fórmula de Ahlbom y Norell (1990) para una mejor cobertura y distribución del tamaño muestral (Cuadro 1).
Se utilizó la prueba intradérmica única de tuberculina con el antígeno PPD bovino (Derivado Proteínico Purificado de M. bovis) para detectar animales sensibilizados a $M$. bovis. Esta prueba se basa en la reacción de hipersensibilidad retardada, como respuesta al antígeno, en la cual participan los linfocitos $\mathrm{T}$ previamente sensibilizados acompañados de macrófagos (Tizard, 1998). La prueba tiene una sensibilidad de $85 \%$ y una especificidad de 98\% (Rebhun, 1995).

La prueba intradérmica se hizo en animales mayores de dos meses de edad, elegidos al azar, a los cuales se les inoculó $0.1 \mathrm{ml}$ $(1 \mathrm{mg} / \mathrm{ml})$ de tuberculina PPD bovina, previa limpieza, en el pliegue caudal izquierdo. La lectura se realizó a las $72 \pm 6$ horas de la inoculación, mediante la observación, palpación y comparación con el pliegue caudal homólogo. Se consideró animales reactores a la prueba de tuberculina a aquellos que presentaron cambios visibles y palpables como engrosamiento e induración de la piel con calor y dolor (reacción de hipersensibilidad retardada) en el punto de inoculación, y se consideraron animales negativos a aquellos que no presentaron o presentaron cambios discretos sin manifestaciones de inflamación.

Se realizó la necropsia a un animal positivo y se tomaron muestras de ganglios linfáticos para ser procesados en el Laboratorio de Histopatología de la Facultad de Medicina Veterinaria de la Universidad Nacional Mayor de San Marcos. La prevalencia relativa o aparente de la tuberculosis caprina con un intervalo de confianza del 95\% fue determinada mediante la fórmula de proporciones de Ahlbom y Norell (1990).

\section{Resultados}

Se encontró dos animales hembras de un mismo hato que fueron reactores (positivos) a la prueba intradérmica de tuberculina PPD bovina, de un total de 412 caprinos muestreados; lo que representa una preva- 
Cuadro 2. Prevalencia de tuberculosis caprina en la provincia de Barranca determinado mediante la prueba intradérmica de tuberculina

\begin{tabular}{|c|c|c|c|c|}
\hline \multirow{2}{*}{ Distritos } & \multirow{2}{*}{$\begin{array}{c}\text { Hatos } \\
\text { muestreados }\end{array}$} & \multicolumn{2}{|c|}{ Animales } & \multirow{2}{*}{$\begin{array}{l}\text { Prevalencia } \\
\text { relativa (\%) }\end{array}$} \\
\hline & & Muestreados & Reactores & \\
\hline Paramonga & 5 & 76 & 0 & \\
\hline Pativilca & 5 & 85 & 0 & \\
\hline Barranca & 3 & 50 & 0 & \\
\hline Supe & 11 & 201 & 2 & \\
\hline Total & 24 & 412 & 2 & $0.48 \%$ \\
\hline
\end{tabular}

lencia relativa o aparente de $0.48 \pm 0.67 \%$ (Cuadro 2).

En la necropsia se observó que los ganglios mesentéricos se encontraron aumentados de tamaño y con material caseoso en su interior. Las muestras de ganglios linfáticos coloreada con hematoxilina-eosina revelaron la presencia de lesiones granulomatosas típicas, con un núcleo caseoso rodeado de células mononucleares y de fibroblastos hacia la periferie; mientras que con la coloración de Ziehl-Neelsen se pudo observar a los bacilos ácido-alcohol resistentes.

\section{Discusión}

La prevalencia de $0.48 \%$ (2/412), indicaría un nivel relativamente bajo de tuberculosis caprina en la provincia de Barranca. Al parecer la baja ocurrencia de tuberculosis se debería al sistema extensivo de crianza que caracteriza a la producción de estos animales en la zona de estudio. Se conoce que el mayor confinamiento de los sistemas intensivos predispone la mayor incidencia de la TBC (Bonilla, 2001; Radostits et al., 2002).

Esta situación ocurre también en el caso de la tuberculosis bovina (Blaha, 1995; Radostits et al., 2002), donde se observa que a medida que aumenta el tamaño de los re- baños, se incrementa proporcionalmente el número de animales reactores a la prueba de tuberculina, en parte dado por el aumento de la densidad y nivel de contacto entre animales (Rivera, 2000).

La convivencia entre caprinos y bovinos favorece la transmisión de la tuberculosis entre especies (Arellano et al., 1999). Aquí, es importante mencionar que el SENASA (Servicio Nacional de Sanidad Agraria) en su programa de control y erradicación de la TBC bovina, reportó dos bovinos reactores a la prueba intradérmica de tuberculina PPD bovina en el distrito de Supe en el 2003 (Dirección Departamental SENASA, Comunicación personal).

En un estudio realizado en España, se describe un genotipo caprino en cepas de $M$. bovis (Gutiérrez et al., 1997). Del mismo modo, Balseiro et al. (2001) hacen referencia de una subespecie de M. bovis (M. bovis caprae) que presenta una mayor afinidad por el ganado caprino.

Por otro lado, a pesar de la existencia de alternativas diagnósticas como la prueba del Gamma-Interferón (INF-?) y Elisa, estas tendrían que estar ampliamente evaluadas en la práctica para usarlas como pruebas de rutina, de allí que el método de detección de animales que padecen de TBC continua sien- 
do la prueba intradérmica única de tuberculina (Radostits et al., 2002).

\section{Litertura Citada}

1. Acha P, Szyfres B. 1986. Zoonosis y enfermedades transmisibles comunes al hombre y los animales. $2^{\mathrm{a}}$. ed. Washington: OPS. 989p.

2. Ahlbom A, Norell S. 1990. Introduction to modern epidemiology. $2^{\text {2d }}$ ed. USA: Epidemiology Resources. $102 \mathrm{p}$.

3. Aiello S, Mays A. 2000. El manual Merck de veterinaria. $5^{\mathrm{a}}$. ed. España: Ed Océano. 2558 p.

4. Arellano A, Ramírez C, DíazA, Valero E, Santillán F. 1999. Diagnóstico de tuberculosis en hatos caprinos empleando la prueba intradérmica doble comparativa y cultivo bacteriológico. Téc Pec Méx 37(1): 55-58.

5. Arroyo O, Matossian C. 2001. Experiencias en producción caprina en la zona de Lima: Limitaciones y perspectivas. Rev Inv Vet, Perú (Supl 1): 154-158.

6. Balseiro A, Prieto J, Espí A, García J. 2001. Estudio epidemiológico de la tuberculosis caprina en Asturias utilizando la técnica de Gamma-Interferón. En: Res XXVI Jornadas Científicas de la Sociedad Española de Ovinotecnia y Caprinotecnia. España. p 671-675.

7. Beer J. 1981. Enfermedades infecciosas de los animales domésticos. Tomo II. Madrid: Acribia. 104 p.

8. Blaha T. 1995. Epidemiología especial veterinaria. España: Acribia. 544 p.

9. Bonilla W. 2001. Producción de cabras lecheras: Manejo sanitario. Chile: INIA.

10. Cotran R, Kumar V, Collins T. 2000. Patología estructural y funcional. $6^{\mathrm{a}}$ ed. España: Ed Mc Graw Hill.

11. Cotrina N. 1987. Epizootiología de la tuberculosis bovina. La Habana, Cuba: Ed. Científico-Técnica. $135 \mathrm{p}$.

12. Daniel WM. 1996. Bioestadística: Bases para el análisis de las ciencias de la salud. 5a. México DF: Ed. Limusa. 878 p.
13. De la Vega E. 1988. La tuberculosis bovina en las distintas especies animales de importancia pecuaria-anatomo-patológica. En: Curso taller sobre Tuberculosis, Brucelosis y Fiebre Aftosa. OPSOMS. Trujillo, Perú.

14. Gázquez A. 1991. Patología veterinaria. España: Ed Interamericana. 501 p.

15. Gutierrez M, Samper S, Jiménez M, Van-Embden J, Marín J, Martín C. 1997. Identification by spoligotyping of a caprine genotype in Mycobacterium bovis strains causing human tuberculosis. J Clin Microbiol 35: 3328-3330.

16. [INEI] Instituto Nacional de Estadística e Informática. 1994. III Censo Nacional Agropecuario. Ministerio de Agricultura.

17. Jubb K, Kennedy P, Palmer N. 1990. Patología de los animales domésticos. $3^{\text {a }}$ ed. Tomo II. Uruguay: Ed. Hemisferio Sur. $653 \mathrm{p}$.

18. Juste R. 1989. Apuntes sobre patología caprina. Dpto. Agricultura y Pesca. Gobierno Vasco, España. [Internet]. Disponible en: http://personal.redestb.es/ rajuste/patcap1.htm

19. Nicolet J. 1986. Compendio de bacteriología médica veterinaria. España: Acribia. 275 p.

20. Perea A, Arenas A, Maldonado A, Tarradas C, Gómez-Villamandos I, Sánchez P, et al. 1999. Patología de los rumiantes en imágenes (II). España. [Internet]. Disponible en: http:// www.colvet.es/infovet/oct99/ciencias_v/ articuloI.htm

21. Prescott L, Harley J, Klein D. 2002. Microbiología. $5^{a}$ ed. España: McGraw Hill- Interamericana. $1026 \mathrm{p}$.

22. Radostits O, Gay C, Blood D, Hinchcliff K. 2002. Medicina veterinaria. $9^{a}$ ed. España: McGraw Hill. 1920 p.

23. Rebhun W. 1995. Enfermedades del ganado vacuno lechero. España: Acribia. $666 \mathrm{p}$.

24. Rivera A. 2000. Experiencias en el saneamiento de tuberculosis bovina en el programa de certificación de predios li- 
bres de la X Región. Taller de Actualización sobre Tuberculosis en Chile. Santiago: SENASA.

25. Tizard I. 1998. Inmunología veterinaria. $5^{a}$ ed. México DF: Mc Graw Hill Interamericana. $567 \mathrm{p}$.
26. Torres P, Martínez M, Bernardelli A, Herrera M, Lizziero M. 2000. Saneamiento de la tuberculosis bovina en un rodeo lechero caprino en la provincia de Buenos Aires. En: II Congreso Argentino de Zoonosis. Buenos Aires. 